\title{
EVALUATION OF MICROSTRUCTURE AND MECHANICAL PROPERTIES OF TITANIUM ALLOY OT 4-1
}

\author{
ANANDA MOHAN VEMULA ${ }^{\mathbf{1}}$, G. CHANDRA MOHAN REDDY ${ }^{2} \&$ M. MANZOOR HUSSAIN ${ }^{3}$ \\ ${ }^{l}$ Research Scholar, Department of ME, JNTUH \& Associate Professor, GNITC Hyderabad, Telangana State, India \\ ${ }^{2}$ Principal, Department of ME, MGIT, Hyderabad, Telangana, India \\ ${ }^{3}$ Professor, Department of ME, JNTU Hyderabad, Telangana, India
}

\begin{abstract}
The aim was first, to determine the microstructure constituents and second to determine the mechanical properties of the sample. In this research, Titanium alloy OT 4-1 sheet was observed by a meta scope metallurgical microscope to evaluate the microstructure. The mechanical properties of the Titanium Alloy OT 4-1 sheet in three different orientations along the rolling direction, 450 in the rolling direction and in the transverse to the rolling direction were observed. The microstructure consists of single phase, i.e. Alpha titanium in a secular matrix at room temperature. It was observed that the yield stress in the transverse direction was more than in the rolling direction and ultimate tensile strength was more in the rolling direction than in the transverse to the rolling direction.

KEYWORDS: OT 4-1, Microstructure, Mechanical Properties \& Titanium Alloy
\end{abstract}

Received: Apr 17, 2017; Accepted: May 18, 2017; Published: May 30, 2017; Paper Id.: IJMPERDJUN201723

\section{INTRODUCTION}

Now a days, there is high demand for some special metals and alloys that can withstand high temperature, corrosion resistance and high strength to weight ratio. [1,9] OT 4-1 is a titanium alloy used for high-temperature application in the aerospace industry. These materials are extensively used in process industries, in paper and textile plants, in extractive metallurgy, in the oil industry, in medical sciences and in some engineering components such as steam and gas turbine blades, connecting rods, crankshafts etc. Hence, the evaluation of its microstructure and mechanical properties are important thereby, it is useful further to study formability aspects. The increasing use of titanium alloys in load bearing elements causes a need for research into their strength characteristics. OT 4-1 is a low alloyed titanium alloy processing a good ductility and low strength. The alloy is based on the Ti-Al-Mn system[7], is intended mainly for sheet semi-products such as structural and also forgings, stampings, rods, shapes, pipes, wire and other semi-products.[3-6]

\section{Titanium and Its Alloys}

Titanium exists in two crystallographic forms:

- Unalloyed titanium i.e., commercially pure titanium has hexagonal close-packed (hcp) crystal structure known as Alpha $(\alpha)$ phase

- At recrystallization temperature, at $882.50 \mathrm{C}$ it transforms into a body-centered cubic (bcc) structure 
- Known as a beta $(\beta)$ phase. [1-2]

\section{There are Three Titanium Alloys Existing Based on the Chemical Composition of the Alloy}

- Alpha $(\alpha)$ alloy is the low-temperature allotrope of Titanium and microstructure consists of Alpha $(\alpha)$ phase.

- Alpha $(\alpha)+$ beta $(\beta)$ alloy, is the high-temperature allotrope of Titanium and microstructure consists of Alpha $(\alpha)$ and beta $(\beta)$ phase.

- The beta $(\beta)$ alloy is the very high-temperature allotrope of Titanium and microstructure consists of beta ( $\beta$ ) phase. [8]

\section{EXPERIMENTATION}

\section{Composition}

The 5mm OT 4-1 sheet was received in cold rolled and annealed condition. The composition of the plates was confirmed by Inductive coupled plasma optical spectrometer technique and found to be Russian grade Titanium alloy OT 4-1. The features of Inductive coupled plasma optical spectrometer were:

- Multi-element, a sequential technique with wavelength range: 190-750 NM

- The Plasma produced by the electrode radio frequency discharge.

- A High-resolution grating with RF source.

- It can produce a very high temperature up to $10,000^{\circ} \mathrm{K}$.

- The Capability of analysis from ppm to percentage level.

The alloy OT 4-1 (Ti-Al-Mn system) has the following chemical composition (Wt \%): Al, $1.0-2.5 ; \mathrm{Mn}, 0.7-2.5$ the content of impurities should be not more than (Wt \%) C, 0.10. [7] The composition of the sheet was given in Table1.

Table 1: Chemical Composition of OT 4-1

\begin{tabular}{|c|c|c|c|c|c|}
\hline Element & Al & Mn & $\mathbf{V}$ & $\mathbf{C}$ & TI \\
\hline$\%$ composition & $1.5-2.5$ & $0.7-2.0$ & - & $\operatorname{Max} 0.1$ & $94.33-97.50$ \\
\hline Experimental values (Wt \%) & 2.24 & 1.44 & 0.048 & 0.002 & 96.158 \\
\hline
\end{tabular}

\section{Microstructure}

For micro structure, specimens of size $20 \times 20 \mathrm{~mm}$ from the material was cut by EDM wire cut machine as shown in Figure 2 and mounted on mounting press as shown in Figure 1 for sample preparation. Experimental sample was prepared with the regular procedure from belt grinding to fine polishing papers, then disc polishing was done with variable speed grinder-polisher, on the velvet cloth. After getting the mirror image, the specimen was etched with $\mathrm{HF}+\mathrm{HNO} 3+$ $\mathrm{H} 2 \mathrm{O}$ and with the Netscape metallurgical microscope with 100X magnification microstructure was observed. The microstructure of the OT 4-1 (Ti2.24Al1.44Mn) in annealed condition was depicted in Figure 2, given below. The microstructure has single phase $\alpha$ structure. 


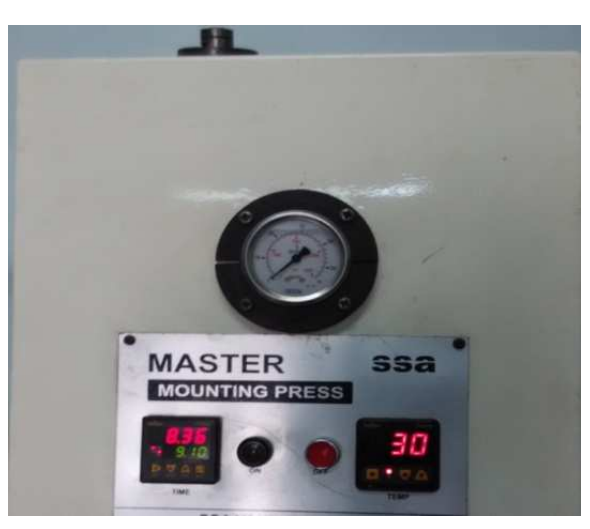

Figure 1: Specimen Mounting Machine

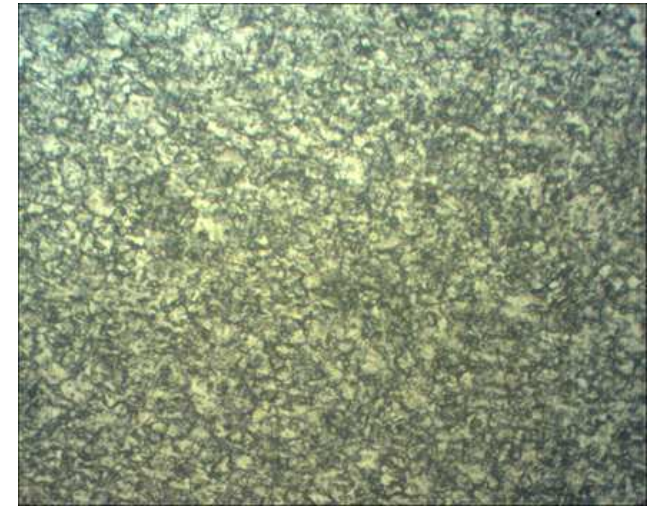

Figure 2: Microstructure of OT 4-1

\section{Mechanical Properties}

The tensile specimens were prepared as per the ASTM E8 standards by a wire-cut EDM. The standard specimen details are shown in Figure 3. [10]

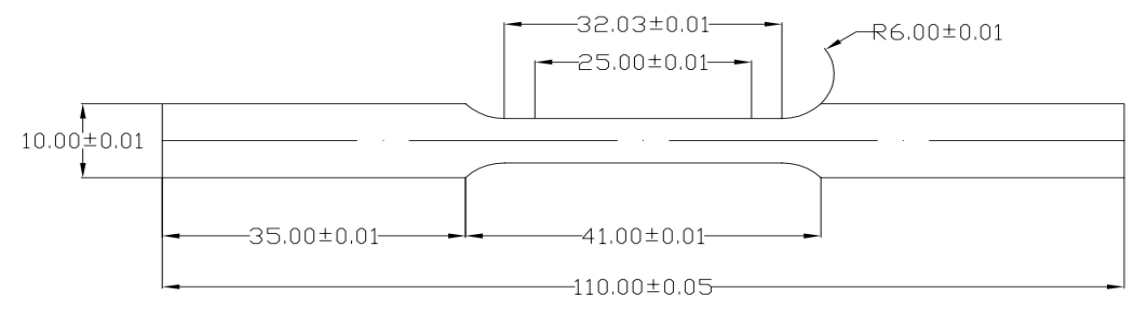

Figure. 3: Standard ASTM E8 Tensile Specimen

The specimens were prepared in different orientations but for the experimental analysis, we considered only three orientations i.e. along the rolling direction (L), $\mathrm{L}+45^{\circ}$, transverse to the rolling direction (LT) as shown in Figure $4 \&$ Figure 5 .

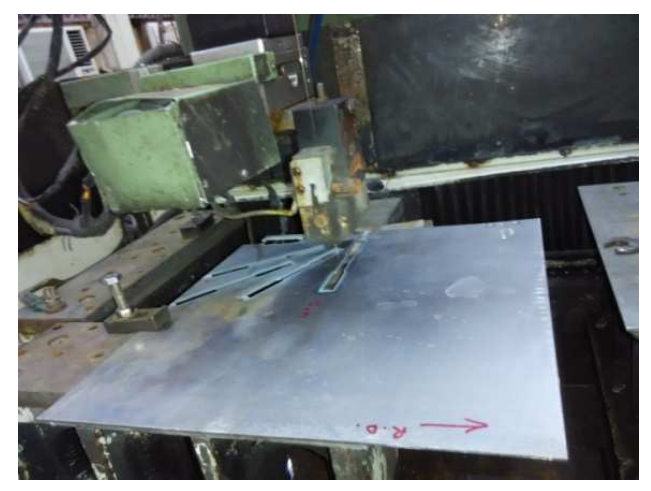

Figure 4: EDM Wire Cut Machine

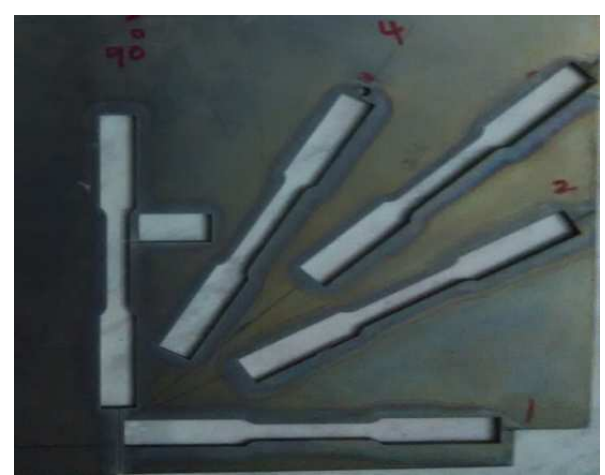

Figure 5: Tensile Specimens in Different Orientations

\section{RESULTS AND DISCUSSIONS}

The mechanical properties of a material should have high strength, high resistance to creep, fatigue, and corrosion. Titanium alloys have remarkable resistance to corrosion by atmosphere, sea water and certain acids 
have found wide applications. Hence the evaluation of mechanical properties has an important role in further research. Some of the details about the tensile test specimen OT 4-1 are given in Table 2.

Table 2: Tensile Test Details of OT 4-1

\begin{tabular}{|c|c|c|c|c|c|}
\hline Specimen Label & $\begin{array}{c}\text { Original Gauge } \\
\text { Length }(\mathbf{m m})\end{array}$ & $\begin{array}{c}\text { Final Gauge } \\
\text { Length }(\mathbf{m m})\end{array}$ & Width(mm) & Thickness( mm) & C/S Area (mm2) \\
\hline OT 4-1- L & 25.00 & 31.82 & 6.01 & 5.01 & 30.11 \\
\hline OT 4-1- L + 45 & 25.00 & 31.50 & 6.03 & 5.01 & 30.21 \\
\hline OT 4-1- LT & 25.00 & 31.96 & 6.00 & 5.01 & 30.06 \\
\hline
\end{tabular}

The mechanical properties of titanium alloy OT 4-1 sheet were given in Table 3. It was observed that Ultimate tensile strength was more in the rolling direction and Yield stress was increased in the transverse to the rolling direction. The maximum Ultimate tensile strength was found to be $767.187 \mathrm{~N} / \mathrm{mm}^{2}$ and Maximum Yield stress was found to be $653.693 \mathrm{~N} / \mathrm{mm}^{2}$.

Table 3. Mechanical Properties of Sheet Metal Titanium Alloy OT 4-1

\begin{tabular}{|c|c|c|c|c|c|}
\hline Specimen Label & $\begin{array}{l}\text { Ultimate Load } \\
(\text { KN) }\end{array}$ & $\begin{array}{l}\text { Ultimate Tensile } \\
\text { Strength }\left(\mathrm{N} / \mathrm{mm}^{2}\right)\end{array}$ & $\begin{array}{l}\text { Yield Load } \\
(\text { KN) }\end{array}$ & $\begin{array}{c}\text { Yield Stress } \\
\left(\mathrm{N} / \mathrm{mm}^{2}\right)\end{array}$ & $\begin{array}{c}\text { Elongation } \\
(\%)\end{array}$ \\
\hline OT 4-1- L & 23.10 & 767.187 & 19.120 & 635.005 & 27.280 \\
\hline OT 4-1- L + 45 & 21.060 & 697.120 & 18.330 & 606.753 & 26.000 \\
\hline OT 4-1- LT & 22.380 & 744.511 & 19.650 & 653.693 & 27.840 \\
\hline
\end{tabular}

The load versus displacement graphs were drawn for three different orientations, in which along the rolling direction, Yield point load was found at $19.120 \mathrm{KN}$ and at the ultimate point the load was $23.10 \mathrm{KN}$, which was observed from Figure 6.

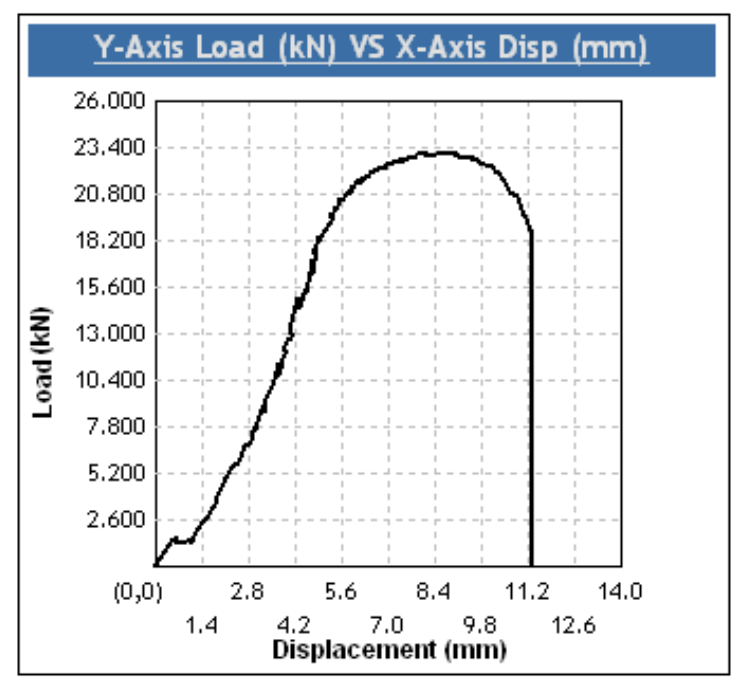

Figure 6: Load Vs Displacement Along the Rolling Direction(L) 


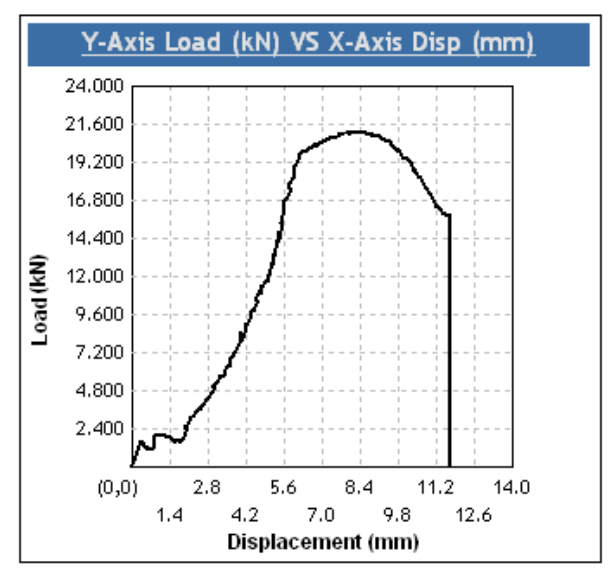

Figure 7: Load Vs Displacement Along the $\mathrm{L}+\mathbf{4 5}^{\circ}$

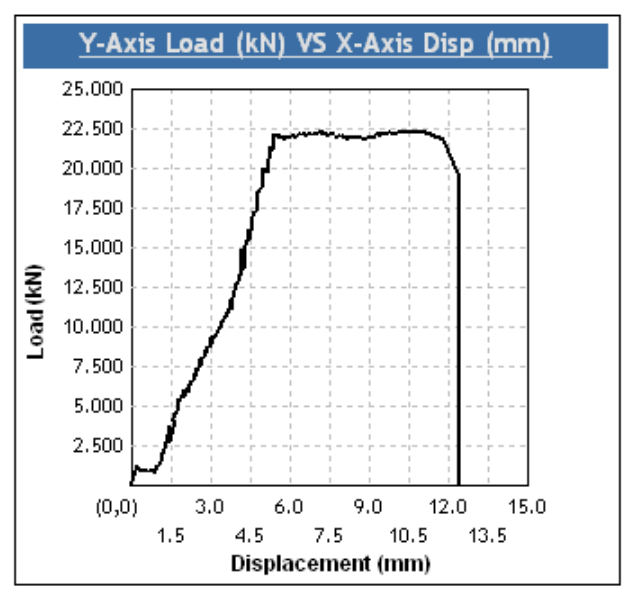

Figure 8: Load Vs Displacement Along the Transverse to the Rolling Direction

The load versus displacement graphs for $\mathrm{L}+45^{\circ}$ and LT directions are shown in Figure 7 and Figure 8 , respectively. It is observed that the yield and ultimate load for $\mathrm{L}+45^{\circ}$ were found as $18.330 \mathrm{KN}$ and $21.060 \mathrm{KN}$, the corresponding values for LT were $19.650 \mathrm{KN}$ and $22.380 \mathrm{KN}$.

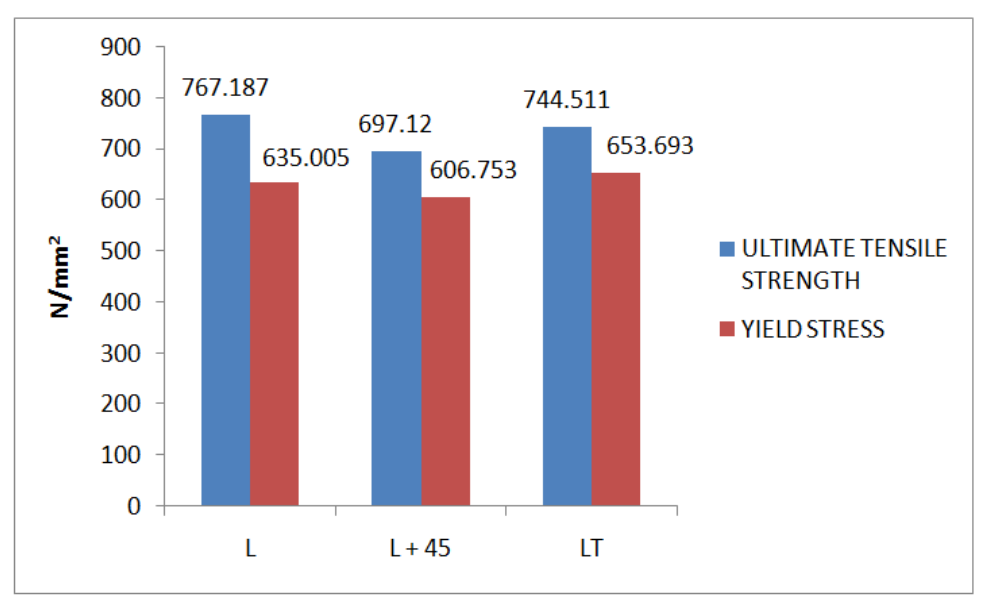

Figure 9: Comparison between Ultimate Tensile Strength and Yield Stress 
Figure 9 shows the comparison between Ultimate Tensile strength (UTS) and Yield stress (Y.S) for the three samples, which were taken for the experimentation.

\section{CONCLUSIONS}

- The Microstructure consists of fine Alpha grains in the matrix of acicular alpha

- The Ultimate Tensile Strength was more in the rolling direction (L).

- $\quad$ The Yield Stress was more in the transverse to the rolling direction (LT).

- $\%$ of elongation were more in the transverse to the rolling direction (LT).

- The microstructure and mechanical properties were useful further for finding the engineering stress and engineering strains, true stresses and true strains, and work hardening exponent.

- The above-said properties were useful for finding the formability characteristics of the material

\section{REFERENCES}

1. Wang, G., Hui, S., Ye, W., Mi, X., Wang, Y., \& Zhang, W. (2012). Microstructure and tensile properties of low-cost titanium alloys at different cooling rate. Rare Metals, 31(6), 531.

2. Fujii, H., Takahashi, K., \& Yamashita, Y. (2003). Application of titanium and its alloys for automobile parts. Shinnittetsu giho, $62-67$

3. Gammon, L. M., Briggs, R. D., Packard, J. M., Batson, K. W., Boyer, R., \& Domby, C. W. (2004). Metallography and microstructures of titanium and its alloys. Materials Park, OH: ASM International, 2004, 899-917

4. Dearnaley, G., \& Watkins, R. E. (1984). U.S. Patent No.4, 465,524. Washington, DC: U.S. Patent and Trademark Office

5. Brunette, D. M., Tengvall, P., Textor, M., \& Thomsen, P. (Eds.). (2012). Titanium in medicine: material science, surface science, engineering, biological responses and medical applications. Springer Science \& Business Media

6. Boyer, R. R. (1996). An overview on the use of titanium in the aerospace industry. Materials Science and Engineering: A, 213(1-2), 103-114

7. V. Moiseyev, Titanium alloys: Russian aircraft and aerospace applications, 1st Edition, CRC Press, Boca Raton, Florida, 2006

8. Lutjering_Titanium-1st_2nd_ed, "Engineering Materials and Processes”, Springer-Verlog Berlin Heidelberg, (2003).

9. Luo J., and Li M.Q., Modeling of grain size in isothermal compression of Ti-6Al-4V alloy using fuzzy neural network, Rare Met., 2011, 30 (6): 555.

10. Metals Handbook, 9th edR, American Society for Metals, Metals Park, OH, 1980, p. 372 